\title{
Fortnightly tides and subtidal motions in a choked inlet
}

\author{
Jamie MacMahan ${ }^{a}, *$, Jacobus van de Kreeke ${ }^{b}$, Ad Reniers ${ }^{b}$, Steve Elgar ${ }^{c}$, \\ Britt Raubenheimer $^{\mathrm{c}}$, Ed Thornton ${ }^{\mathrm{a}}$, Micah Weltmer ${ }^{\mathrm{a}}$, Patrick Rynne ${ }^{\mathrm{b}}$, Jenna Brown ${ }^{\mathrm{a}}$ \\ a Oceanography Department, Naval Postgraduate School, Monterey, CA 93933, USA \\ ${ }^{\mathrm{b}}$ Applied Marine Physics, University of Miami, Miami, FL 33149, USA \\ ${ }^{c}$ Woods Hole Oceanographic Institution, WHOI, MA 02543, USA
}

\section{A R T I C L E I N F O}

\section{Article history:}

Received 21 May 2013

Accepted 27 March 2014

Available online 13 April 2014

\section{Keywords:}

tidal choking

tide

nonlinear response

fortnightly response

subtidal signal

tidal wave propagation

inlet

\begin{abstract}
A B S T R A C T
Amplitudes of semi-diurnal tidal fluctuations measured at an ocean inlet system decay nearly linearly by $87 \%$ between the ocean edge of the offshore ebb-tidal delta and the backbay. A monochromatic, dynamical model for a tidally choked inlet separately reproduces the evolution of the amplitudes and phases of the semi-diurnal and diurnal tidal constituents observed between the ocean and inland locations. However, the monochromatic model over-predicts the amplitude and under-predicts the lag of the lower-frequency subtidal and fortnightly motions observed in the backbay. A dimensional model that considers all tidal constituents simultaneously, balances the along-channel pressure gradient with quadratic bottom friction, and that includes a time-varying channel water depth, is used to show that that these model-data differences are associated with nonlinear interactions between the tidal constituents that are not included in non-dimensional, monochromatic models. In particular, numerical simulations suggest that the nonlinear interactions induced by quadratic bottom friction modify the amplitude and phase of the subtidal and fortnightly backbay response. This nonlinear effect on the lowfrequency (subtidal and fortnightly) motions increases with increasing high-frequency (semi-diurnal) amplitude. The subtidal and fortnightly motions influence water exchange processes, and thus backbay temperature and salinity.
\end{abstract}

Published by Elsevier Ltd.

\section{Introduction}

As tidal waves propagate from the ocean through an inlet and into the backbay (lagoon), amplitudes decrease and phase lags develop relative to the oceanic sea-surface elevation fluctuations. If the amplitude reduction is large, the system is considered tidally choked. Tidal choking influences the amount of flushing from the lagoon to the ocean, which is important to coastal ecology, water quality, and sedimentation. Coastal lagoons have been divided into three categories (choked, restricted, and leaky) based on the ability of the lagoon to flush water (Kjerfve, 1986). Tidal choking occurs if there is a relatively long, narrow, or shallow channel connected to a backbay with a large surface area (Brown, 1928; Bruun et al., 1978; Hill, 1994) (Fig. 1). Most observations of tidal choking are associated with shallow coastal lagoons that typically are found in microtidal regimes with flat coastal plains (Kjerfve, 1986). Tidal choking also is observed in larger, deeper, narrow channel inlet systems with

\footnotetext{
* Corresponding author.

E-mail address: jhmacmah@nps.edu (J. MacMahan).
}

backbays (e.g. Indian River Inlet, DE, USA (Wong and Lu, 1994) and Fleet Lagoon, English Channel, UK (Robinson et al., 1983)).

The channel of a tidally choked inlet system acts like a hydraulic low-pass filter between the ocean sea-surface fluctuations and the backbay response (Di Lorenzo, 1988; Kjerfve and Knoppers, 1991). There is relatively greater damping of high-frequency, large amplitude tidal motions than of low-frequency, small amplitude tidal motions, and the phase difference between the ocean and backbay sea-surface fluctuations decreases with decreasing frequency (Keulegan, 1967). A number of relatively simple tidal (choking) models exist that describe the tidal amplitude decay and temporal lag in the backbay forced by oceanic tidal amplitudes and phases at the entrance of the inlet without (Keulegan, 1967; Stigebrant, 1980) and with (Hill, 1994) tidally varying channel water depths. In these models the ocean is connected to the backbay via a prismatic channel, resulting in linear amplitude decay along the channel owing to bottom friction (Fig. 1).

Models that account for a time-varying water depth suggest that the frictional effect decreases during flood tides and increases during ebb tides (Hill, 1994). This frictional asymmetry allows water to flow more easily into the backbay than out to the ocean, 

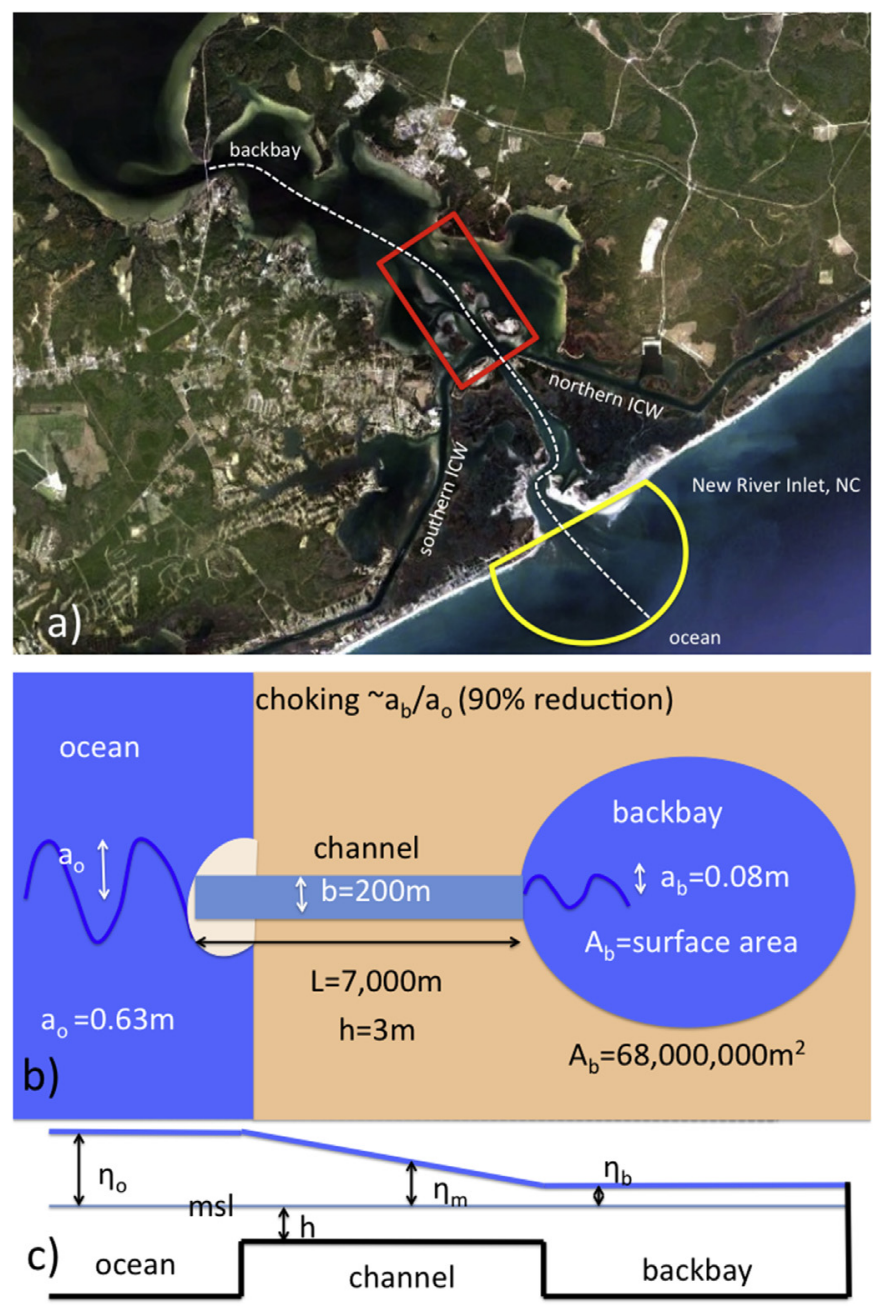

Fig. 1. a) Google Earth image of New River Inlet, NC showing the Atlantic Ocean, the backbay, the northern and southern ICW, the main channel (white dashed curve), the dredge spoil (red box), and the ebb-tidal delta (yellow semi-circle). b) Plan form and c) profile view of the tidal-choking model with dimensional inlet features of New River Inlet, NC. $a_{o}$ is the ocean M2 tidal amplitude, $a_{b}$ is the backbay M2 tidal amplitude, $b$ is the channel width, $L$ is the channel length, $h$ is the channel water depth, $A_{b}$ is the backbay surface area, and $\eta_{o}, \eta_{m}$, and $\eta_{b}$ are the surface elevations at the ocean, channel, and backbay, respectively. (For interpretation of the references to color in this figure legend, the reader is referred to the web version of this article.)

resulting in a set-up in the backbay sea-surface elevation. Time varying water depths owing to M2 and S2 tides induce a nonlinear fortnightly elevation response in the backbay that depends on the amount of tidal choking and the channel water depth (Hill, 1994).

Here, observations of sea-surface elevation obtained in the large, tidally choked inlet system at New River Inlet, NC, are used to drive a dynamical model to predict the corresponding backbay response, including the long time lags between low-frequency (aperiodic subtidal and periodic fortnightly) motions in the backbay and the ocean. For previous tidal choking models (Keulegan, 1967; Bruun et al., 1978; Stigebrant, 1980; Di Lorenzo, 1988; Hill, 1994; Albrecht and Vennell, 2007) the governing equations were written in a non-dimensional form parameterized by the amplitude and period of a single tidal constituent, restricting the application of the governing equations to a single (monochromatic) tidal constituent. Thus, these models cannot simulate the nonlinear interactions between multiple tidal constituents. In contrast, here a dimensional tidal choking model applicable to all tidal constituents simultaneously is used in combination with the field observations to investigate the nonlinear effects of the semi-diurnal (M2, S2) and diurnal $(\mathrm{K} 1, \mathrm{O} 1)$ tides on the generation and propagation of aperiodic low-frequency subtidal and fortnightly (MSF) motions commonly observed in the ocean (Hill, 1994; Wong and Lu, 1994; amongst others). The influence of the subtidal and fortnightly motions on water temperature and salinity is described.

\section{Field observations}

Observations were obtained in May 2012 at New River Inlet, NC. This system has an ebb-tidal delta that is approximately $1 \mathrm{~km}$ in radius on the ocean side. The channel that connects the ocean to the large surface area $\left(68 \mathrm{~km}^{2}\right)$ backbay is relatively long $(7000 \mathrm{~m})$, narrow (200 m), and shallow (3 m) (Fig. 1a,b). The primary channel and the interconnecting Intracoastal Waterway (ICW) (Fig. 1a) are dredged to maintain shipping navigation. Dredge spoil usually is placed next to the primary channel and in the ICW (Fig. 1a). The placement of the dredge spoil in the backbay increased the length of the tidal channel and has created the appearance of a flood-tidal delta (Fig. 1a, red box). There are additional inlets connecting the ICW to the ocean $12 \mathrm{~km}$ to the north and $36 \mathrm{~km}$ to the south (not shown). The proximity of these neighboring inlets affects the tidal wave interaction as it propagates into the inlet and then along the ICW (described below).

Short- ( $\sim 1$ day) and long- ( $\sim 3$ weeks) term pressure measurements were obtained using pressure sensors with $\pm 0.5 \mathrm{~cm}$ accuracy throughout the ocean, inlet, backbay, and both north and south of New River within the ICW (Fig. 2). The absolute subaqueous pressure signal was corrected for atmospheric pressure fluctuations. A suite of instruments was attached to one of six, easily moved small floating catamarans ("mini-cats") that were anchored to the seabed. A pressure sensor sampling at $1 \mathrm{~Hz}$ was attached to the mini-cat anchors to measure sea-surface elevation. Measurements were obtained for $t>24$ h so that tidal harmonic analysis (T_TIDE, Pawlowicz et al., 2002) could be performed to determine the approximate amplitudes and phases of the diurnal, semi-diurnal, and higher harmonic tidal constituents of the detrended sea-surface elevation observations by a least-squares fit. In addition to the short-term deployments, long-term ( $\sim 3$ weeks) pressure measurements were obtained outside of the ebb-tidal delta in $9-\mathrm{m}$ water depth (inlet $\mathrm{km} 0$, Fig. 3) and in the backbay (inlet km 10, Fig. 3).

\section{Field experiment results}

\subsection{Tidal constituents}

At the ocean boundary, the tidal signal is dominated by the M2 tidal constituent (period $T=12.42 \mathrm{~h}$, amplitude $a=0.63 \mathrm{~m}$ )(not shown). The other relevant tidal constituents are K1 (lunisolar, $T=23.94 \mathrm{~h}, a=0.11 \mathrm{~m}$ ), S2 (principal solar, $T=12 \mathrm{~h}, a=0.08 \mathrm{~m}$ ), 01 (principal lunar, $T=25.82 \mathrm{~h}, a=0.08 \mathrm{~m}$ ), and MSF (lunar-solarfortnightly, $T=354.37 \mathrm{~h}, a=0.15 \mathrm{~m}$ ). The tidal constituents represent $93 \%$ of the variance, implying that the signal is primarily tidal. The M2 amplitude decreases with distance into the backbay ( $a=0.08 \mathrm{~m}$, Figs. 2 and 3 ), and with distance along the ICW channels (Fig. 2). The amplitude decrease is larger in the southern ICW channel than in the northern ICW channel, possibly owing to the different distances to the neighboring inlets. While the amplitude of the M2 constituent (derived from the short-term estimates) decreases with distance from the ocean (Fig. 2a), the temporal lag increases (Fig. 2b). Lags are larger in the southern ICW channel than in the northern ICW channel, consistent with stronger tidal choking in the southern channel. The southern channel has reduced 

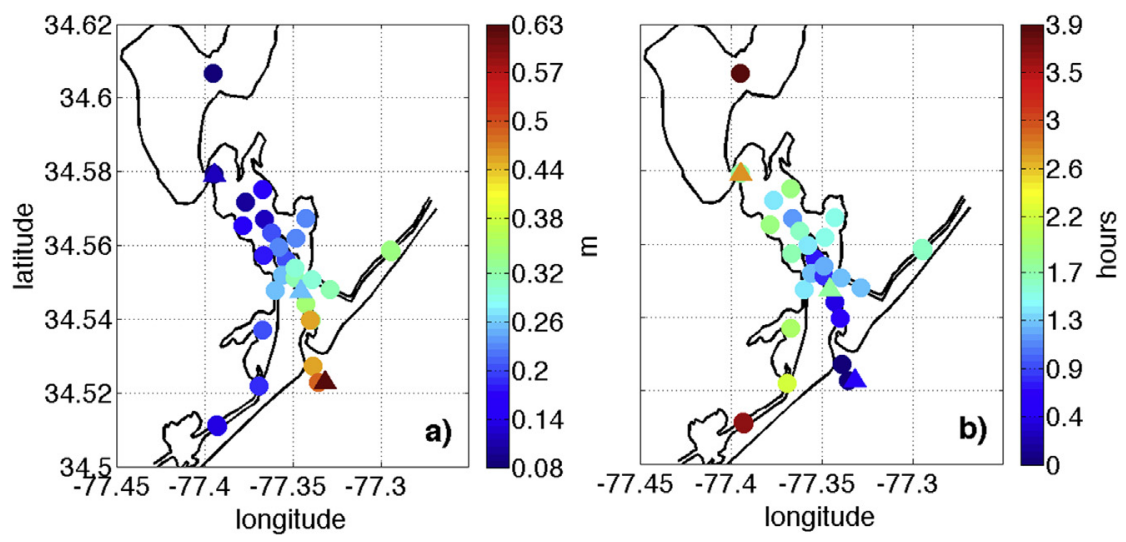

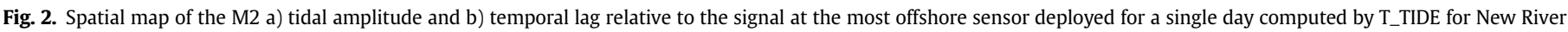

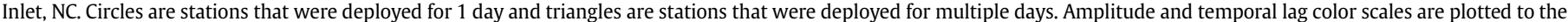

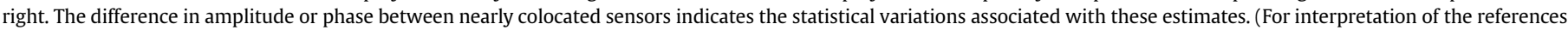
to color in this figure legend, the reader is referred to the web version of this article.)

exchange, resulting in a hyper-saline system (Sheets, 2013). The northern channel has larger tidal amplitudes than the southern channel, and tends to exchange water with the inlet to the north. Despite morphological irregularity along the (non-prismatic) channel, the along-channel M2 amplitude has a near linear decay for approximately $7000 \mathrm{~m}$ before leveling off in the backbay (Fig. 3), consistent with the assumption in the simple dynamical tidal model used here.

\subsection{Frequency bands}

Backbay surface elevation fluctuations have a larger number of significant tidal constituents than the offshore fluctuations, including overtides and harmonics associated with nonlinear coupling of fundamental constituents, notably M2 and S2. Consistent with previous studies (Nidzieko, 2010) the presence of the nonlinearities cause the tidal motions to be spread among neighboring frequencies, increasing the difficulty of comparing the primary tidal constituents measured in the ocean with those measured in the backbay. Owing to this spectral smearing, the ocean and backbay tidal "time" signals were filtered into four period bands (semi-diurnal $(T<15 \mathrm{~h})$, diurnal $(15<T<28 \mathrm{~h})$, subtidal $(1.5<T<10$ days), fortnightly ( $T>10$ days)), and evaluated separately. The semi-diurnal signal, which includes M2, S2, and high-frequency fluctuations, is largest at the ocean $(a \sim 0.8 \mathrm{~m})$, and has an $87 \%$ reduction in amplitude and $2.5 \mathrm{~h}$ time lag in the backbay relative to the ocean (Fig. 4a). The diurnal signal, which includes $\mathrm{K} 1, \mathrm{O} 1$, and diurnal wind forcing, has an ocean amplitude of $\sim 0.2 \mathrm{~m}$ during the spring modulation (Fig. $4 \mathrm{~b}$ ). The diurnal amplitude decay and time lag between the ocean and backbay are

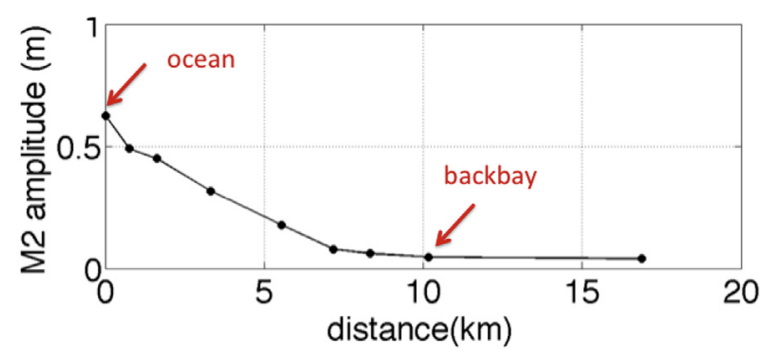

Fig. 3. M2 tidal amplitude versus along-channel distance from the ocean to the backbay. Arrows indicate the location of the long-term ocean and backbay sensors.
$60 \%$ and $5 \mathrm{~h}$, respectively. The subtidal signal (Fig. 4c) is aperiodic $(a \sim 0.15 \mathrm{~m}$ ), and does not correspond to a known tidal constituent. The subtidal amplitude decay and time lag vary, and on average are $55 \%$ and $6 \mathrm{~h}$, respectively (Fig. 4c). The fortnightly signal $(a \sim 0.08 \mathrm{~m}$, Fig. 4d), which includes the MSF tidal constituent and lowerfrequency motions, has a $20 \%$ reduction in amplitude and a $29 \mathrm{~h}$ lag (Fig. 4d). The increase in fortnightly backbay elevation on yearday 138 is not observed in the ocean (Fig. 4d). The highfrequency motions tend to decay more than the low-frequency motions, consistent with previous work on tidal choking and supporting the notion that a choked inlet behaves as a low-pass filter (Keulegan, 1967; Kjerfve and Knoppers, 1991). However, the temporal lag for the MSF tidal constituent is much longer than the few hour lag expected from a tidal-choking model (Keulegan, 1967).

\section{Tidal inlet hydrodynamics}

\subsection{Model}

Neglecting advection, the steady state, depth and along-channel integrated along-channel momentum equation results in a balance between a pressure gradient and bottom friction, given by Hill (1994)

$g=\frac{\eta_{o}-\eta_{b}}{L}=-\frac{k u|u|}{h+\eta_{m}}$

a)

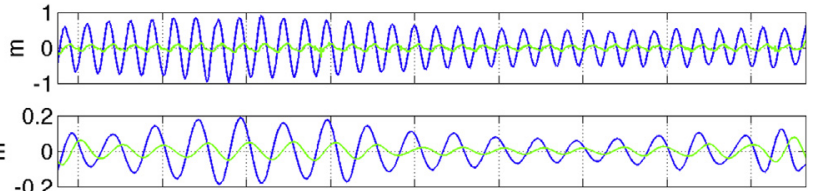

b)

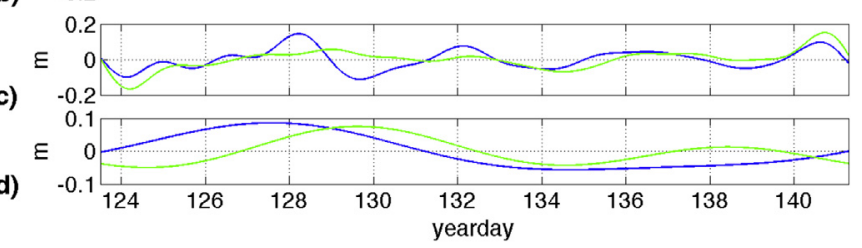

Fig. 4. a) Semi-diurnal, b) diurnal, c) subtidal, and d) fortnightly tidal fluctuations measured in the ocean (blue) and in the backbay (green) versus time. (For interpretation of the references to color in this figure legend, the reader is referred to the web version of this article.) 
where

$\eta_{m}=\frac{\eta_{o}+\eta_{b}}{2}$

is the water level in the channel (which can be constant or can vary in time) relative to the spatially and temporally constant depth $h$ of the channel below mean sea level, $\eta_{o}$ and $\eta_{b}$ are the water levels at the ocean and backbay locations, $g$ is the gravitational acceleration, $L$ is the channel length, $k=0.004$ is a dimensionless friction coefficient (Rydberg and Wickbom, 1996), and $u$ is the along-channel velocity (Fig. 1). The continuity equation for the basin is

$A_{b} \frac{d \eta_{b}}{d t}=-b\left(h+\eta_{m}\right) u$

where $A_{b}$ is the surface area of the backbay, and $b$ is the channel width. Solving for $u$ in Eq. (1) and substituting into Eq. (3) results in

$\frac{d \eta_{b}}{d t}=\left(\frac{g b^{2}}{A_{b}^{2} k L}\left(h+\eta_{m}\right)^{3}\right)^{1 / 2} \frac{\eta_{o}-\eta_{b}}{\sqrt{\left|\eta_{o}-\eta_{b}\right|}}$.

Previous approaches (Hill, 1994; Stigebrant, 1980) nondimensionalized Eq. (4) by, and, where $a_{o}$ is the amplitude of the ocean tidal constituent, yielding (Hill, 1994):

$\frac{d \eta_{b}^{\prime}}{d t^{\prime}}=P\left(1+\frac{a_{o}}{h}\left(h+\eta_{m}^{\prime}\right)^{3}\right)^{1 / 2} \frac{\eta_{o}^{\prime}-\eta_{b}^{\prime}}{\sqrt{\left|\eta_{o}^{\prime}-\eta_{b}^{\prime}\right|}}$,

where

$P=\left(\frac{g b^{2} T^{2} h^{3}}{A_{b}^{2} k L a_{o}}\right)^{1 / 2}$

and $a_{0} / h$ are the non-dimensional parameters. The variable responsible for tidal choking is represented by $P$ (Stigebrant, 1980; Hill, 1994). Eq. (6) depends on $T$ and $a_{0}$, and therefore each tidal constituent has its own $P$ value, and must be solved for independently. However, by solving for the tidal constituents independently, the nonlinear coupling associated with the time-varying water depth [i.e., $\left(h+\eta_{m}\right)^{3 / 2}$ ) and the quadratic friction $\left(u^{2}\right)$ is neglected, or if the tidal constituents are summed using the M2 normalization (Hill, 1994) the signal is not filtered appropriately. Therefore, instead of solving Eq. (5) with a constant $P$ as done by all previous authors, Eq. (4) is solved numerically with a fourth-order Runge-Kutta scheme, allowing all tidal constituents to be solved for simultaneously. This approach includes the nonlinear coupling, accounts for aperiodic motions, and provides for a more realistic description of the tidal propagation.

\subsection{Frequency band model results}

The non-monochromatic, dimensional model (Eq. (4)) with the measured ocean sea-surface elevation and temporally constant water depth in the inlet channel predicts the semi-diurnal sea-surface tidal fluctuations well (Fig. 5a, Table 1). The model underpredicts the diurnal modulation during the spring cycle, but predicts the neap cycle more accurately (Fig. 5b, Table 1). Modeled subtidal fluctuations are sometimes over and sometimes under predicted, and sometimes lag and sometimes lead the observations (Fig. 5c, Table 1). The model under-predicts slightly the backbay fortnightly response (Fig. $5 \mathrm{~d}$, Table 1 ). On average, the constant water depth model predicts the semi-diurnal and diurnal backbay response better than it predicts the subtidal and fortnightly motions.

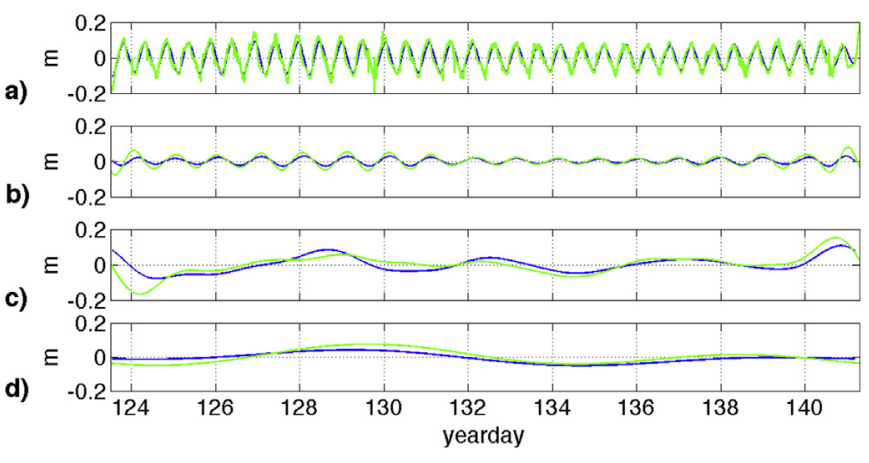

Fig. 5. a) Semi-diurnal, b) diurnal, c) subtidal, and d) fortnightly sea-surface elevation measured (green) and modeled (blue) in the backbay for constant water depth in the inlet channel versus time. The model requires approximately 1.5 days of spin-up, so there is a mismatch between the model results and observations for yeardays 123124. (For interpretation of the references to color in this figure legend, the reader is referred to the web version of this article.)

The backbay response is modeled (Eq. (4)) more accurately by allowing the channel water depth to vary in time. Although there is little change in the prediction of the semi-diurnal response (compare Fig. 5a with 6a, Table 1), model skill is improved during the spring cycle for the diurnal motions (compare Fig. $5 \mathrm{~b}$ with $6 \mathrm{~b}$, modeled amplitudes are larger than in the constant water depth predictions, Table 1), and for both spring and neap cycles for aperiodic subtidal (compare Fig. 5c with $6 c$, Table 1 ) and fortnightly (compare Fig. 5d with 6d, Table 1) amplitudes and phases.

Model skill is reduced if the fluctuations in the different frequency bands are modeled independently (monochromatic), suggesting that the nonlinear interactions between motions are important. In particular, without nonlinear interactions the modeled semi-diurnal (Fig. 7a, Table 1) and diurnal (Fig. 7b, Table 1) responses are less accurate than if nonlinearities are included (compare Fig. 6a with Fig. 7a, and Fig. 6b with Fig. 7b, Table 1). Similarly, without nonlinearities, the modeled aperiodic subtidal amplitude is over predicted and phasing is incorrect (compare Fig. $6 c$ with $7 c$, Table 1) and the modeled fortnightly phasing is incorrect (compare Fig. 6d with 7d, Table 1).

\section{Fortnightly variations in backbay water level}

There are two types of fortnightly response. The astronomical tidal constituent, referred to as MSF, has a tidal period of 14.77 days. This motion is forced at the ocean entrance and is associated with gravitational effects of the moon and the sun. The ocean sensor measured the astronomical MSF sea-surface elevation. The second fortnightly response develops in the backbay as a nonlinear

Table 1

Model skill for three scenarios: 1) constant channel water depth (Figure 5), 2) varying channel water depth (Fig. 6), and 3) independently (monochromatic) for semi-diurnal, diurnal, subtidal, and fortnightly time signals (Fig. 7). The model skill between the measured and modeled estimates is given by the non-dimensional root-mean-square error (NRMSE) defined as the root-mean-square error divided by the range of the signal amplitude, the cross-correlation value $(R)$, and the lag to maximum correlation (lag).

\begin{tabular}{|c|c|c|c|c|c|c|c|c|c|}
\hline \multirow[t]{2}{*}{$\begin{array}{l}\text { Temporal } \\
\text { tidal band }\end{array}$} & \multicolumn{3}{|c|}{$\begin{array}{l}\text { Constant channel } \\
\text { depth }\end{array}$} & \multicolumn{3}{|c|}{$\begin{array}{l}\text { Varying channel } \\
\text { depth }\end{array}$} & \multicolumn{3}{|c|}{ Monochromatic } \\
\hline & $\begin{array}{l}\text { RMS } \\
(\mathrm{m})\end{array}$ & $R$ & $\begin{array}{l}\text { lag } \\
\text { (hr) }\end{array}$ & $\begin{array}{l}\text { RMS } \\
(\mathrm{m})\end{array}$ & $R$ & $\begin{array}{l}\text { lag } \\
\text { (hr) }\end{array}$ & $\begin{array}{l}\text { RMS } \\
(\mathrm{m})\end{array}$ & $R$ & $\begin{array}{l}\text { lag } \\
\text { (hr) }\end{array}$ \\
\hline Diurnal & 0.02 & 0.92 & 0.5 & 0.02 & 0.93 & 0.5 & 0.29 & 0.47 & 0.5 \\
\hline Semi-diurnal & 0.02 & 0.93 & 0.5 & 0.01 & 0.94 & 0.4 & 0.14 & 0.86 & -0.9 \\
\hline Subtidal & 0.04 & 0.75 & 4.7 & 0.02 & 0.89 & 2.2 & 0.15 & 0.65 & -0.5 \\
\hline Fortnightly & 0.02 & 0.84 & -2.7 & 0.01 & 0.93 & -0.5 & 0.23 & 0.67 & -20.3 \\
\hline
\end{tabular}




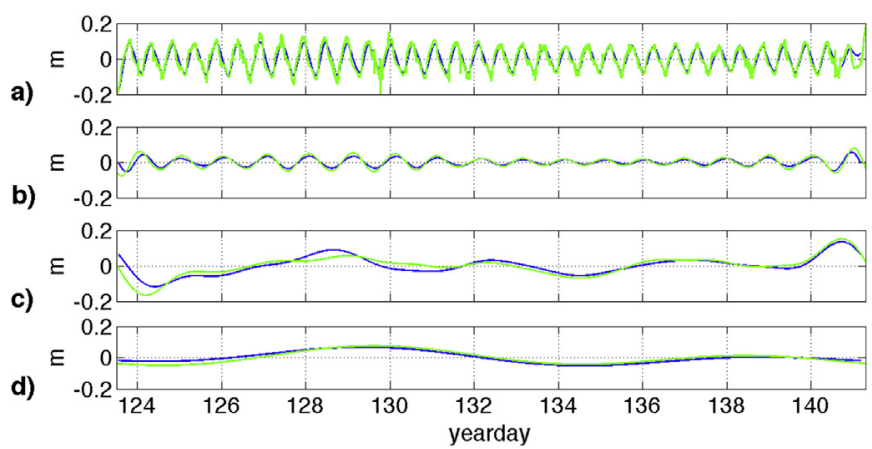

Fig. 6. a) Semi-diurnal, b) diurnal, c) subtidal, and d) fortnightly sea-surface elevation measured (green) and modeled (blue) in the backbay for time-varying water depth in the inlet channel versus time. (For interpretation of the references to color in this figure legend, the reader is referred to the web version of this article.)

response owing to the modulation of M2 and S2 and the effects of tidal choking (Hill, 1994). The nonlinear response period is associated with the frequency difference between M2 and S2, which also has a tidal period of 14.77 days. It has been shown numerically (Hill, 1994) that the nonlinear response is a function of the tidal choking and water depth, and decreases with increasing choking and increasing water depth. The backbay response to different ocean forcing and to different characteristics of the inlet channel is investigated with numerical experiments using the dimensional model (Eqn. (4), Hill, 1994) that includes time-varying channel depths (NE, Table 2).

The fortnightly backbay response to the fortnightly ocean signal (Fig. 8a, red curve) includes minimal amplitude decay relative to the ocean in the backbay and no temporal lag (NE1, Fig. 8b, red curve). The lack of temporal lag is inconsistent with the observations (Fig. 8b, black dashed curve). The fortnightly backbay response to the semi-diurnal ocean signal (Fig. 8a, cyan), which includes the nonlinear coupling by the modulation of M2 and S2, results in an $\sim 0.03 \mathrm{~m}$ nonlinear fortnightly response in the backbay (NE2, Fig. 8b, cyan), similar to previous results (Hill, 1994). This nonlinear backbay response is too small to explain the observed fortnightly backbay response, suggesting that the measured fortnightly backbay response is forced primarily by the MSF astronomical forcing, with a smaller contribution by the M2 and S2 modulation.

When forced with the fortnightly plus the diurnal and semidiurnal ocean signals, which include modulations by M2 and S2, and $\mathrm{K} 1$ and $\mathrm{O} 1$ (Fig. 8a, green), the modeled backbay fortnightly

a)
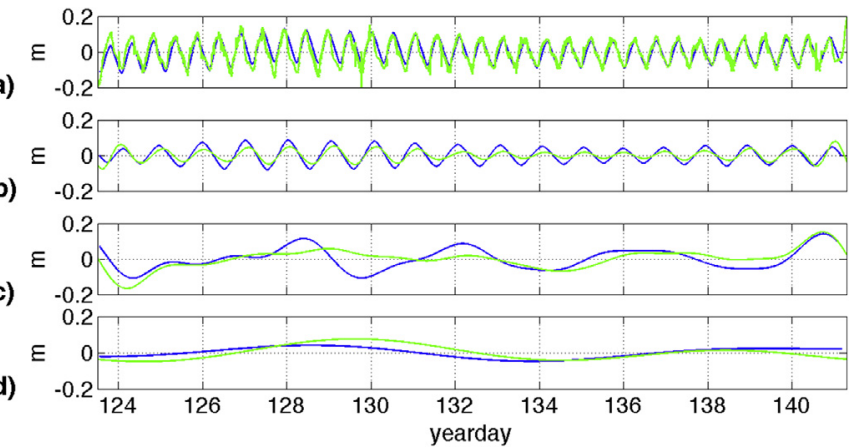

Fig. 7. a) Semi-diurnal, b) diurnal, c) subtidal, and d) fortnightly sea-surface elevation measured (green) and modeled (blue) in the backbay, including time-varying water depth in the inlet channel, but solved for independently versus time. (For interpretation of the references to color in this figure legend, the reader is referred to the web version of this article.)
Table 2

Description of Numerical Experiments (NE). Simulations 1-4 and 14-15 were forced with observations (data), whereas the rest were forced with simulated time series, with the forcing ocean (input) and backbay frequency responses described. The lag in days between the ocean MSF simulated signal and the modeled MSF signal are provided.

\begin{tabular}{|c|c|c|c|c|c|}
\hline $\begin{array}{l}\text { Numerical } \\
\text { experiment }\end{array}$ & Ocean input signal & Data & Simulated & $\begin{array}{l}\text { Backbay } \\
\text { response }\end{array}$ & $\begin{array}{l}\text { Lag } \\
\text { (days) }\end{array}$ \\
\hline 1 & Fortnightly & $\mathrm{x}$ & & Fortnightly & \\
\hline 2 & Semi-diurnal & $\mathrm{x}$ & & Fortnightly & \\
\hline 3 & $\begin{array}{l}\text { Fortnightly, diurnal, } \\
\text { semi-diurnal }\end{array}$ & $\mathrm{x}$ & & Fortnightly & \\
\hline 4 & Fortnightly, subtidal & $\mathrm{x}$ & & Fortnightly & \\
\hline 5 & $\operatorname{MSF}(\theta=0), \mathrm{M} 2, \mathrm{~S} 2$ & & $\mathrm{x}$ & Fortnightly & -0.50 \\
\hline 6 & $\operatorname{MSF}(\theta=90), \mathrm{M} 2, \mathrm{~S} 2$ & & $\mathrm{x}$ & Fortnightly & -0.56 \\
\hline 7 & $\operatorname{MSF}(\theta=180), \mathrm{M} 2, \mathrm{~S} 2$ & & $\mathrm{x}$ & Fortnightly & -0.71 \\
\hline 8 & MSF, M2 & & $\mathrm{x}$ & Fortnightly & -0.61 \\
\hline 9 & MSF, $\mathrm{M} 2, \mathrm{~h}=$ constant & & $\mathrm{x}$ & Fortnightly & -0.56 \\
\hline 10 & $\begin{array}{l}\text { MSF, M2, linear } \\
\text { bottom friction }\end{array}$ & & $\mathrm{x}$ & Fortnightly & 0.00 \\
\hline 11 & MSF, $f=0.04 \mathrm{cpd}$ & & $\mathrm{x}$ & Fortnightly & -0.62 \\
\hline 12 & $\mathrm{MSF}, \mathrm{M} 2=2 \mathrm{a}$ & & $\mathrm{x}$ & Fortnightly & -1.00 \\
\hline 13 & MSF, $M 2=0.5 \mathrm{a}$ & & $\mathrm{x}$ & Fortnightly & -0.37 \\
\hline 14 & Subtidal & $\mathrm{x}$ & & Subtidal & \\
\hline 15 & $\begin{array}{l}\text { Subtidal, diurnal, } \\
\text { semi-diurnal }\end{array}$ & $\mathrm{x}$ & & Subtidal & \\
\hline
\end{tabular}

amplitude response is too low, but the temporal lag is consistent with the measurements (NE3, Fig. 8b, green). Thus, the higherfrequency tidal constituents influence the MSF propagation into the backbay, inducing a temporal lag that does not occur with MSF forcing only (Fig. 8b, red).

The observed subtidal motions have an amplitude of approximately $0.20 \mathrm{~m}$ at the ocean, and decay by about $55 \%$ to the backbay. The simulated fortnightly backbay response driven by the fortnightly plus the subtidal ocean signal (Fig. 8a, blue) increases in amplitude, but not enough to match the measurements, and there is no temporal lag (NE4, Fig. 8b, blue). The temporal lag appears to be induced by the diurnal and semi-diurnal motions, and all motions contribute to the amplitude. When the model is driven by the entire ocean signal (Fig. 8a, magenta), the backbay fortnightly response best matches the observed response (Fig. $8 \mathrm{~b}$, magenta), highlighting the importance of all sources.

The 18-day observational period is relatively short compared with the $\sim 14$ day fortnightly response, and thus harmonic analysis results in a spreading of backbay tidal constituents over neighboring frequencies. To investigate nonlinear effects between M2,

a)
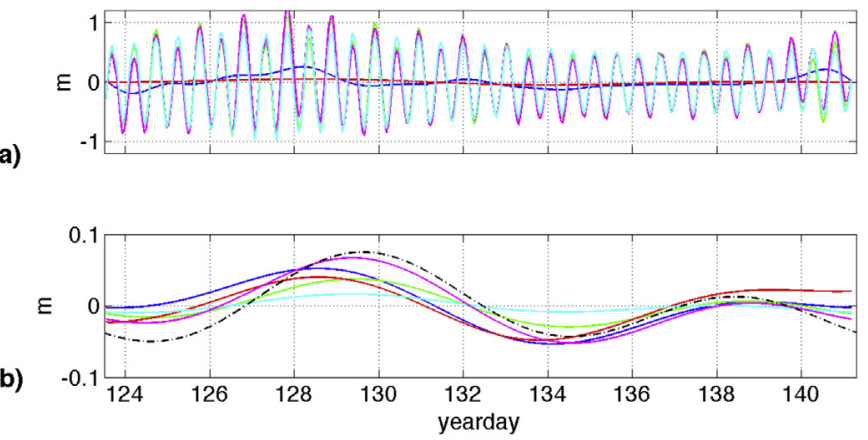

Fig. 8. a) The measured ocean sea-surface elevation versus time for: MSF only (red, NE1), semi-diurnal (includes M2 and S2) (cyan, NE2), MSF plus semi-diurnal and diurnal (includes M2, S2, K1, and 01) (green, NE3), MSF plus subtidal signal (blue, NE4), and entire signal (magenta). b) The fortnightly modeled sea-surface elevation in the backbay corresponding to the ocean inputs described in a). Black dashed curve is the measured sea-surface elevation in the backbay. (For interpretation of the references to color in this figure legend, the reader is referred to the web version of this article.) 
S2, and MSF, simulations (NE5-NE13, Table 2) are forced with a 28day long (two fortnightly cycles) ocean sea-surface time series generated from T_TIDE derived amplitudes and phases for MSF, M2, and S2 at New River Inlet.

To explore the M2 and S2 modulated frictional asymmetry influence on the fortnightly backbay response, the model is forced with M2, S2, and MSF signals for which the MSF amplitude is held constant, but the MSF phase is shifted by $0^{\circ}, 90^{\circ}$ and $180^{\circ}$ (NE5NE7). The backbay fortnightly response is similar for all three phases, except there are slight differences in temporal lag (Table 2). The cross-correlation between the ocean and backbay indicates a temporal lag of $-0.50,-0.56$, and -0.71 days for $0^{\circ}, 90^{\circ}$, and $180^{\circ}$. The spring-neap modulation has a slight effect on the temporal lag of the MSF signal as it propagates into the backbay.

The M2 and S2 constituents have almost the same frequency, but the M2 amplitude is much greater than the $\mathrm{S} 2$ amplitude, so the response to forcing by M2 and MSF is simulated. When driven by an ocean signal consisting of M2 plus MSF (NE8) the fortnightly backbay response has minimal amplitude decay, but a temporal lag (Table 2). The cross-correlation between the MSF in the ocean and backbay has a temporal lag of -0.61 days. When the water depth is held constant in the model (NE9) a -0.56 day temporal lag is generated between the MSF in the ocean and backbay that is slightly different from the time-varying water depth model results (Table 2). Linearizing the bottom friction in Eq. (1) by $k u$, instead of $k u|u|$ results in no temporal lag, suggesting the nonlinearity of the bottom friction is the most important contributor to the temporal lag.

To investigate the influence of the M2 component on the backbay response, simulations with different M2 amplitudes and with the M2 amplitude applied at the K1 frequency ( 0.04 cycles per hour, $\mathrm{cph}$ ) were performed (NE11-NE13). When the amplitude of M2 is applied at the K1 frequency and added to the MSF in the ocean forcing, the temporal lag at the maximum of the crosscorrelation is -0.62 days for $0.04 \mathrm{cph}$, consistent with the temporal lag of the frequency ( $0.08 \mathrm{cph}$ ) of M2 (Table 2), suggesting changing the frequency of the forcing has a minimal effect on the temporal lag for constant amplitude.

In contrast, variation of the M2 amplitude has significant impact on the temporal lag of the MSF backbay response. Doubling the amplitude results in -1 day lag and halving the amplitude results in a -0.37 day lag (Table 2). The amplitude of the M2 tidal constituent is large relative to $\mathrm{K} 1, \mathrm{~S} 2$, and $\mathrm{O} 1$, and thus has the largest impact on the MSF response in the backbay.

In summary, the fortnightly backbay response is associated primarily with the MSF astronomical forcing at the ocean (NE1), which has minimal amplitude decay, but a temporal lag in the backbay. The fortnightly backbay response to nonlinear coupling between M2 and S2 is small (NE2), but there is a slight difference in temporal lag that depends on the phasing of the MSF relative to the M2 and S2 modulation (NE5 to NE7). The primary contributor of the MSF temporal lag is from the M2 tidal constituent (NE8) through the quadratic bottom friction (NE10) that induces a nonlinear response. The time-varying water depth has a minimal effect on the temporal lag with the inclusion of M2 (NE9). Thus, including all components of the sea-surface elevation fluctuations at the ocean boundary is necessary to predict the backbay response (Eq. (4)).

\subsection{Subtidal and fortnightly influence on backbay exchange}

Subtidal (including fortnightly) motions are important to inlet exchange (Wong and Lu, 1994). The amplitude of the subtidal motions measured at the ocean boundary of New River Inlet are $\sim 0.2 \mathrm{~m}$, with a temporal scale of a few days (Fig. 4c, blue curve). The subtidal sea-surface fluctuations along $700 \mathrm{~km}$ of the coast, from Beaufort, NC, south to Cape Canaveral, FL, are similar (correlated at the $95 \%$ confidence interval), suggesting that the subtidal motions at New River Inlet, NC, are not locally driven.

The numerical simulations suggest that the backbay response to subtidal motions is similar to the response to fortnightly motions, with higher-frequency tidal constituents modifying the lowerfrequency motions. The modeled backbay subtidal response (NE14, Fig. 9b, green curve) driven with the measured subtidal ocean signal (Fig. 9a, green curve) differs from the observations (Fig. 9b, black dashed curve) both in amplitude and phase. Including the measured high-pass filtered semi-diurnal and diurnal (M2, S2, K1, and O1) signals (Fig. 9a, blue curve) with the measured subtidal signal (Fig. 9a, green curve) results in a subtidal backbay response (NE15, Fig. 9b, blue curve) that is consistent with the observed amplitude and phase (Fig. 9b, black curve).

To understand the influence of the subtidal and fortnightly motions on the exchange of water between the ocean and the backbay, temperature, salinity, and streamwise velocity measurements are evaluated. Water temperature was measured in the backbay $10 \mathrm{~km}$ from the ocean, and temperature (near the seafloor), salinity (near the sea surface), and vertical profiles of velocity were measured for 9 days in the longitudinal center of the main inlet channel $(4 \mathrm{~km})$, referred to as the mid-station.

The water temperatures (Fig. 10a) and salinity (Fig. 10b) fluctuate with semi-diurnal and diurnal tides. The temperature in the backbay oscillated between 21 and 26 C. For yeardays 133 to 139 the temperature is warmer in the backbay than at mid-station. The backbay water is warmer possibly because it is not exchanged efficiently offshore owing to tidal choking, allowing solar radiation to warm the backbay water relative to the ocean (Fig. 10a). During this period, the ocean water temperature was $\sim 22.5 \mathrm{C}$, and for the most part does not extend as far inland as the backbay station. A tidal intrusion temperature front was observed to develop at about $7.5 \mathrm{~km}$, where the backbay widens.

The inverse relationship between the observed backbay subtidal sea-surface elevation and temperature (Fig. 10d) suggests that cold ocean water is transported by the shoreward subtidal velocities (Fig. 10c), with the corresponding mass flux producing an increase in the water level in the backbay. There also is an inverse relationship between fortnightly sea-surface elevation and temperature (Fig. 10e). There is a positive correlation between subtidal velocity and subtidal pressure [compare the red curve (subtidal velocity) in Fig. 10c with the blue curve (subtidal water elevation) in Fig. 10d). These results suggest that the subtidal and fortnightly flows are important for exchange between the backbay and ocean.

a)
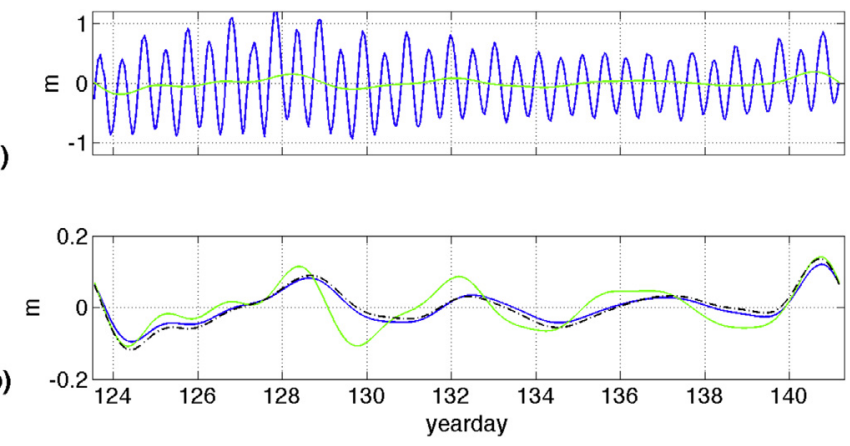

Fig. 9. a) Measured ocean sea-surface elevation for the subtidal (green) and the highfrequency tidal constituents (blue), and b) modeled subtidal sea-surface elevation in the backbay for the ocean subtidal signal only (green, NE14) and for the subtidal plus high-frequency tidal constituents (blue, NE15) versus time. The black dashed curve is the measured subtidal response in the backbay. (For interpretation of the references to color in this figure legend, the reader is referred to the web version of this article.) 
a)

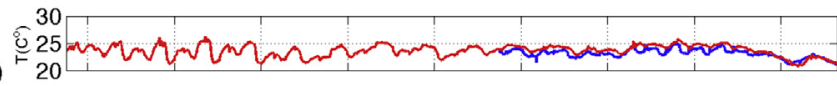

$$
\text { 言 } 30
$$

b) 30

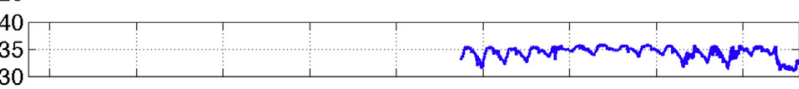

c) $\frac{\widehat{D}}{\mathrm{E}}{ }^{2}$
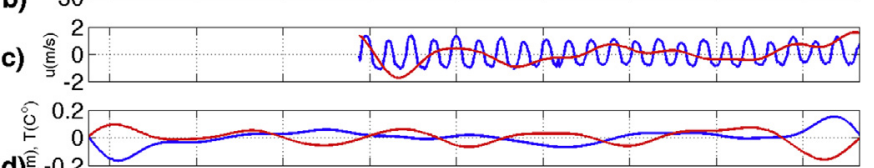

d)

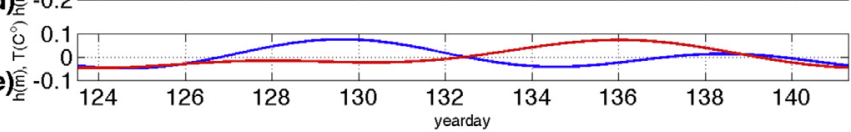

Fig. 10. a) Water temperature for the backbay (red) and mid-station (blue), b) salinity for the mid-station, c) streamwise velocity (blue) and subtidal streamwise velocity multiplied by 10 (red) at the mid-station, and d) subtidal water elevation (blue) and subtidal temperature (divided by 10 , red) in the backbay, and e) fortnightly water elevation (blue) and fortnightly temperature (divided by 5 , red) in the backbay versus time. Positive velocity is flow into the backbay. (For interpretation of the references to color in this figure legend, the reader is referred to the web version of this article.)

\section{Summary and conclusions}

Observations of an $87 \%$ reduction in the amplitude of the semidiurnal tidal constituent at New River Inlet, NC, suggest that the estuary system is tidally choked. There is a near linear decay in the semi-diurnal amplitude from the ebb-tidal delta to the end of the channel that opens up in the backbay, validating an assumption in previously proposed dynamical tidal models (Keulegan, 1967; Stigebrant, 1980; Hill, 1994). The inlet behaves as a low-pass hydraulic filter (Kjerfve and Knoppers, 1991), resulting in different backbay amplitude and phase responses for the semi-diurnal, diurnal, subtidal, and fortnightly signals. The observed backbay subtidal and fortnightly surface elevations are not simulated accurately by a monochromatic tidal-choking model (e.g. Keulegan, 1967). In contrast, a simple, non-monochromatic, dimensional model that balances pressure gradients with bottom friction, and that includes a tidally varying water depth and allows nonlinear interactions between constituents predicts accurately the backbay subtidal and fortnightly response. Numerical experiments demonstrate that there is nonlinear coupling via the quadratic bottom friction primarily between the relatively large M2 tidal constituent and the subtidal and fortnightly ocean signals. The temporal lag of the low-frequency signal is increased with increasing high-frequency (M2) amplitude. The nonlinear coupling between MSF and M2 is important to the fortnightly backbay response. The subtidal and fortnightly motions transport colder, saline ocean water into the backbay, and increase sea levels in the estuary, and thus the nonlinear coupling between tidal constituents must be considered to predict the subtidal and fortnightly exchange of waters between the backbay and ocean.

\section{Acknowledgments}

We thank the many people who helped, obtain the field observations during both nice days and some fairly horrid days, the USACE Field Research Facility for bathymetry and logistical support, and the Office of Naval Research (N0001411WX20962; N0001412WX20498) for funding. We thank the two anonymous reviewers for improving the clarity of this work.

\section{References}

Albrecht, N., Vennell, R., 2007. Tides in two constricted New Zealand lagoons. N. Z. J. Mar. Freshw. Res. 41 (1), 103-118.

Brown, E.L., 1928. Inlets on sandy coasts. Proc. Am. Soc. Civ. Eng. 54, 505-553.

Bruun, P., Metha, A.J., Johnson, I.G., 1978. Stability of Tidal Inlets. Elsevier Scientific Publishing Company, Amsterdam, p. 510.

Di Lorenzo, J.L., 1988. The overtide and filtering response of small inlet-bay systems, In: Aubrey, D.G., Weishar, L. (Eds.), Hydrodynamics and Sediment Dynamics of Tidal Inlets. Springer-Verlag, pp. 24-54.

Hill, A.E., 1994. Fortnightly tides in a lagoon with variable choking. Estuar. Coast. Shelf Sci. 38, 423-434.

Keulegan, G.H., 1967. Tidal flow in estuaries, water level fluctuations of basins in communication with seas. Comm. Tidal Hydraul., Army Corps Eng. Vicksbg. Miss., Tech. Bull. 4, 89 .

Kjerfve, B., 1986. Comparative oceanography of coastal lagoons. In: Wolfe, D.A. (Ed.), Estuarine Variability. Academic, San Diego, California, pp. 63-81.

Kjerfve, B., Knoppers, B.A., 1991. Tidal-choking in a coastal lagoon. In: Parker, B. (Ed.), Tidal Hydrodynamics. John Wiley, N.Y, pp. 169-181.

Nidzieko, N.J., 2010. Tidal asymmetry in estuaries with mixed semidiurnal/diurnal tides. J. Geophys. Res. 115, C08006. http://dx.doi.org/10.1029/2009JC005864.

Pawlowicz, R., Beardsley, B., Lentz, S., 2002. Classical tidal harmonic analysis including error estimates in MATLAB using T_TIDE. Comput. Geosci. 28, 929937.

Robinson, I.S., Warren, L., Longbottom, J.F., 1983. Sea-level fluctuations in the Fleet, an English tidal lagoon. Estuar. Coast. Shelf Sci. 16, 651-668.

Rydberg, L., Wickbom, L., 1996. Tidal-choking and bed friction in Negombo Lagoon, Sri Lanka. Estuaries 19-3, 540-547.

Sheets, J., 2013. Salinity, Temperature, and Optical Characterization of a TidallyChocked Estuary Connected to Two Contrasting Intra-coastal Waterways. Naval Postgraduate School, pp. 1-27. M. Sc. thesis.

Stigebrant, A., 1980. Some aspects of tidal interactions with fjord constrictions. Estuar. Coast. Shelf Sci. 11, 151-166.

Wong, K.-C., Lu, X., 1994. Low-frequency variability in Delaware's inland bays. J. Geophys. Res. 99, 12,683-12,695. 